\title{
Transport of Explosive Residue Surrogates in Saturated Porous Media
}

\author{
Beth Lavoie • Melanie A. Mayes • Larry D. McKay
}

Received: 18 May 2011 / Accepted: 12 October 2011 / Published online: 3 November 2011

(C) The Author(s) 2011. This article is published with open access at Springerlink.com

\begin{abstract}
Department of Defense operational ranges may become contaminated by particles of explosives residues (ER) as a result of low-order detonations of munitions. The goal of this study was to determine the extent to which particles of ER could migrate through columns of sandy sediment, representing model aquifer materials. Transport experiments were conducted in saturated columns $(2 \times 20 \mathrm{~cm})$ packed with different grain sizes of clean sand or glass beads. Fine particles (approximately 2 to $50 \mu \mathrm{m}$ ) of 2,6dinitrotoluene (DNT) were used as a surrogate for ER. DNT particles were applied to the top $1 \mathrm{~cm}$ of sand or beads in the columns, and the columns were subsequently leached with artificial groundwater solutions. DNT migration occurred as both dissolved and particulate phases. Concentration differences between unfiltered and filtered samples indicate that particulate DNT accounted for up to $41 \%$ of the mass recovered in effluent samples. Proportionally, more particulate than dissolved DNT was recovered in effluent
\end{abstract}

B. Lavoie $(\bowtie) \cdot$ L. D. McKay

Department of Earth and Planetary Sciences, University of Tennessee,

1412 Circle Drive,

Knoxville, TN 37996, USA

e-mail: bethshebal@gmail.com

M. A. Mayes

Environmental Sciences Division, Subsurface Science

Group, Oak Ridge National Laboratory,

Oak Ridge National Laboratory,

Oak Ridge, TN 37831-6038, USA solutions from columns with larger grain sizes, while total concentrations of DNT in effluent were inversely related to grain size. Of the total DNT mass applied to the uppermost layer of the column, $<3 \%$ was recovered in the effluent with the bulk remaining in the top $2 \mathrm{~cm}$ of the column. Our results suggest there is some potential for subsurface migration of ER particles and that most of the particles will be retained over relatively short transport distances.

Keywords Colloid transport · Dinitrotoluene · Munitions $\cdot$ Nitroaromatics $\cdot$ Sand

\section{Introduction}

Contamination of near-surface soil by explosives residues (ER) is a common problem at former and active Department of Defense (DoD) firing ranges. The use of high explosives during training exercises often leaves significant concentrations of ER particles in soils which, in some cases, may subsequently infiltrate into underlying aquifer systems. In both the USA and Canada, plumes of dissolved ER have been observed in groundwater at a limited number of ranges, e.g., Massachusetts Military Reservation (MMR) in MA, Joint Base Lewis-McChord in WA, and Canadian Forces Base in Valcartier, Quebec, Canada (Clausen et al. 2006; Jenkins et al. 2001; Thiboutot et al. 1998). 
One of the most common explosives currently employed by the DoD is Composition B (CB) (Taylor et al. 2006). The main constituents of $C B$ are: 2,4,6trinitrotoluene (TNT) and hexahydro-1,3,5-trinitro1,3,5-triazine (RDX), which are proportionally by mass $39.5 \%$ and $59.5 \%$, respectively, with an additional 1\% paraffin wax. Octahydro-1,3,5,7-tetranitro1,3,5,7-tetrazocine (HMX) is also often present as an impurity in the RDX (up to 10\%). All three chemical constituents have relatively low solubility (approximately 4 to $120 \mathrm{mg} \mathrm{L}^{-1}$ ) which should limit their potential to contaminate groundwater (Morley et al. 2006). However, the solubility values are substantially above the health advisory guidance levels for all three$0.002 \mathrm{mg} \mathrm{L}^{-1}$ for TNT and RDX, and $0.4 \mathrm{mg} \mathrm{L}^{-1}$ for HMX (USEPA 2009a). In addition, sorption experiments indicate that RDX and HMX, and to a slightly lesser degree TNT, have low distribution coefficients $\left(K_{\mathrm{d}}\right)$ which may promote less retention and greater migration in groundwater (Dontsova et al. 2006; Clausen et al. 2006). Hence, even with limited solubility, CB residue could pose both ecological and public health risks.

Although progress has been made towards expanding our knowledge of the chemical and physical properties of explosives compounds, efforts to develop predictive fate and transport models to determine the potential impact of training range activities on groundwater have proven challenging. The most common conceptual models in the literature are based on the assumption that solid explosive residues in soils are dissolved by infiltrating precipitation at or near the ground surface and subsequently leached through the vadose zone as a dissolved phase (Hewitt et al. 2005; Clausen et al. 2006). However, at some sites (e.g., MMR), RDX concentrations in the groundwater exceed anticipated levels based on measured concentrations in the vadose zone, solubility calculations, and measured partition coefficients (Clausen et al. 2006). This suggests the possibility that transport of ER in the solid phase, as colloids, or as dissolved phase compounds adsorbed to colloidal soil materials (i.e., clays, oxides, and/or organic matter) could be contributing to groundwater contamination.

The movement of colloids can play a significant role in the transport of some types of contaminants. Colloidal contaminants (e.g., bacteria, viruses) or contaminants adsorbed to natural colloids (e.g., clay particles, organic material) are often transported faster in groundwater than are dissolved constituents (McCarthy and Zachara 1989). As colloids are excluded by size from diffusion into fine-grained soil or rock matrices, their movement is restricted to macropores where soil and ground water velocities can greatly exceed those expected based on bulk hydraulic conductivity (McCarthy and McKay 2004).

Previous studies examining the size distribution of explosives residues have focused almost exclusively on the centimeter to millimeter pieces as potential sources of contamination (Jenkins et al. 2006; Taylor et al. 2004). However, the same studies also reported the occurrence of fine explosives residues $(<250 \mu \mathrm{m})$ coincident to the deposition of the larger fragments (Jenkins et al. 2006; Taylor et al. 2004, 2009b). In addition, experiments examining the fate of ER residues on ranges provide anecdotal evidence that larger pieces of ER tend to disaggregate into smaller particles due to weathering (Taylor et al. 2009b). Given the low solubility values for ER, it is possible that micron- to sub-micron-sized particles could be mobilized as colloids. The transport of fine ER particles could contribute to the downward migration of explosives compounds through the vadose zone to underlying aquifers. Because this conceptual model has not been investigated with respect to ER, the primary goal of this study was to determine the potential for solid-phase transport of ER in a simple model aquifer system. A secondary objective was to determine the influence of grain size on the mobility of ER in granular sediments.

\section{Materials and Methods}

2.1 Preparation and Particle Size Analysis of Surrogate Particulate ER

The compound 2,6-dinitrotoluene (DNT) was used as an analog for ER. While not a direct constituent of $\mathrm{CB}$, it is also a nitroaromatic with a similar chemical structure and comparable solubility (approximately $200 \mathrm{mg} \mathrm{L}^{-1}$ ) and distribution coefficient values (Luning Prak and O'Sullivan 2007; Pennington et al. 2003). DNT was used as a non-explosive surrogate in this study to provide valuable information on transport processes and aid in design of future experiments with actual explosive compounds. We 
recognize that DNT is more representative of TNT than the other constituents of CB, RDX, or HMX, but it is the best surrogate available for these types of experiments.

Crystalline DNT (Sigma Aldrich, Ultra Scientific ( $\geq 98 \%$ purity) was ground to a fine powder using a porcelain mortar and pestle. Transmitted-light brightfield microscopy and automated image analysis software (NIS-Elements v3.0, Nikon, Melville, NY, USA) were used to determine the size distributions of the DNT powder. Slides for the microscopic analysis were prepared by applying a small ( $10 \mathrm{mg})$ sample of DNT powder on a glass slide, adding $5 \mu$ of tap water, and then sandwiching the suspension between the slide and coverslip. Initial observations of the water-DNT suspensions showed that clusters (or flocs) of the finely ground DNT particles quickly formed in the water. A $1 \%$ bovine serum albumin (BSA) solution was used for the particle size analyses to prevent flocculation. BSA is often used as a dispersant, e.g., in the medical application of carbon nanoparticles (Elgrabli et al. 2007). Results from Suttiprasit et al. (1992) show that the addition of $1 \mathrm{~g}$ of BSA per liter of water (with a $0.01 \mathrm{M}$ phosphate buffer of $7 \mathrm{pH}$ ) lowered the surface tension of the solution by approximately $20 \%$ which can reduce the flocculation of suspended particles. Treatment with BSA allowed for a homogeneous suspension of particles in the solution, enabling more accurate analyses of the particle size distribution. Subsequently, BSA was also added to the influent solution of the particulate DNT column transport experiments to prevent the formation of aggregates.

The automated size distribution analysis is based on particle equivalent diameter. Assuming a spherical geometry, the equivalent diameter is calculated using the total area of the particle, determined from the twodimensional microscopic image. The bulk of the particles detected in the DNT powder were between 2 and $50 \mu \mathrm{m}$ in diameter ( $98 \%$ by number) (Fig. 1$)$, while a small number of larger particles (ranging from 50-88 $\mu \mathrm{m}$ ) were also detected. The lower limit resolution of the microscope used to perform the analysis was approximately $2 \mu \mathrm{m}$. It is possible that there were particles of $<2-\mu \mathrm{m}$ diameter in the DNT powder, but they could not be detected or resolved as individual particles. While not spherical, most of the particles observed were sub-rounded to sub-angular in shape, so the equivalent diameter calculations should accurately estimate the size of the particles.

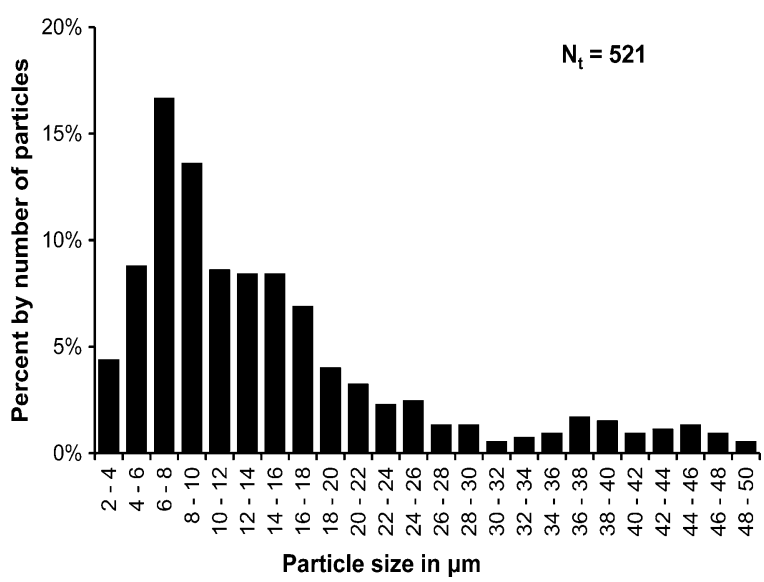

Fig. 1 DNT particle distribution. Particle size distribution of the DNT powder presented as percent by number of particles per approximate diameter range. $N_{\mathrm{t}}$ is the total number of particles counted. Particles $>50 \mu \mathrm{m}$ were scarce $(<3 \%$ by number) and were not included in this figure. Also, the lower limit resolution of the microscope used to perform the particle size distribution analysis was approximately $2 \mu \mathrm{m}$. Therefore, it is possible that there were particles of $<2 \mu \mathrm{m}$ diameter in the DNT powder but they could not be detected or resolved as individual particles

\subsection{Column Experiments}

A series of saturated flow experiments were conducted utilizing 2-cm-diameter $\times 20$-cm-long vertical, clear, polyvinyl chloride columns. Acid-washed Ottawa sand or glass beads were packed into the columns using a standard tap and fill method (Snyder and Kirkland 1979). The glass beads were $4 \mathrm{~mm}$ in diameter, and two different grain sizes of sand were used. One was characterized, using ASTM protocols, as a medium- to fine-grained sand $\left(d_{50}=0.374 \mathrm{~mm}\right)$, herein referred to as "fine sand", and the other was characterized as a medium-grained sand $\left(d_{50}=\right.$ $1.04 \mathrm{~mm}$ ), herein referred to as "medium sand" (Fetter 1994). The porosity of the columns was inferred by the measured difference between dry and saturated mass. A summary of the materials used and conditions for each experiment is provided in Table 1 .

In each experiment, the column was slowly saturated from the bottom with a background solution of $0.005 \mathrm{M} \mathrm{CaCl}_{2}$ artificial groundwater (AGW). Saturated hydraulic conductivity $\left(K_{\text {sat }}\right)$ was measured using a constant head technique (Table 1$)$. After $K_{\text {sat }}$ tests were complete, the influent entry point was switched from the bottom to the top of the column. All experiments were performed using an infusion 
Table 1 Summary of column transport experimental conditions

\begin{tabular}{llcccc}
\hline Experiment ID & Pack type & Median grain size $(\mathrm{mm})$ & Porosity & Hydraulic conductivity $(\mathrm{cm} / \mathrm{h})$ & Flow velocity $(\mathrm{cm} / \mathrm{h})$ \\
\hline FS & Fine sand & 0.4 & 0.33 & $4.25 \mathrm{E}+02$ & $3.85 \mathrm{E}+02$ \\
MS & Medium sand & 1.0 & 0.31 & $1.28 \mathrm{E}+03$ & $4.10 \mathrm{E}+02$ \\
GB & Glass beads & 4.0 & 0.43 & $9.58 \mathrm{E}+02$ & $2.98 \mathrm{E}+02$ \\
\hline
\end{tabular}

${ }^{\text {a }}$ Flow velocity determined using Darcy's equation

pump with a constant input $\left(Q_{\text {in }}\right)$ at a rate of $400 \mathrm{~mL} \mathrm{~h}^{-1}$ which corresponds to a specific discharge rate (flow per unit area) of $130 \mathrm{~cm} \mathrm{~h}^{-1}$. Such high velocities are unlikely to occur under field conditions, except in localized areas, such as bomb craters, where surface runoff might accumulate. However, because the study is designed to determine if ER particles can migrate through soils, a rapid flow rate was chosen to maximize potential for mobility. Prior to the introduction of the influent solution and/or particle material, columns were flushed with a minimum of six pore volumes (PV) of AGW. The top end cap of the column was then removed, and approximately half the sand from the top $1 \mathrm{~cm}$ long segment of the column was scooped out and placed in a weighing boat. A pre-measured quantity of particulate DNT ( $\sim 50 \mathrm{mg}$ ) was thoroughly mixed with the sand from the column. The DNT/sand mixture was then gently repacked in the top layer of the column. Once repacked, a small amount $(<0.5 \mathrm{~mL})$ of background solution was applied directly to the DNT/sand mixture to re-saturate the top layer of the column. Finally, the end cap was replaced and flow resumed by pumping influent solution into the top of the column.

All influent solutions consisted of AGW with $1 \mathrm{gL}^{-1}$ of BSA added as a particulate dispersant. The addition of BSA to the influent solution is expected to increase the mobility of the DNT particles, by decreasing the tendency of the particles to flocculate. This should reduce retention of particles in the sediment and hence will tend to provide a measure of the upper limit of DNT particle transport in this material. For the glass bead experiment, the influent solution was also supplemented with a conservative tracer [0.001 M Bromide (Br)]. Approximately 7 PV was pumped through each column after the addition of the DNT/sand mixture. All effluent was captured with a continuous fraction collector (ISCO, Retriever IV). Effluent samples ( $\sim 3.5 \mathrm{~mL})$ were split into two equal-volume aliquots. One aliquot was passed through a nylon syringe filter $(0.2 \mu \mathrm{m}$ pore size $)$ to remove particles present in the effluent. Based on our analysis, adsorption of DNT to the nylon syringe filter used to process the effluent samples was within the analytical error. Herein, filtered effluent samples are referred to as "dissolved DNT" and unfiltered samples as "Total DNT". We interpret higher concentrations in the total DNT samples relative to dissolved DNT samples to indicate the presence of particulate DNT in the effluent. Upon completion of the transport experiments, each saturated column was quickly sealed and frozen to prevent further transport or dissolution of particulate DNT. The freezing process also helped to facilitate the sectioning of the columns into subsamples. Once frozen, the column was sliced into $1-\mathrm{cm}$ sections using a pipe-cutter.

\subsection{Detection Methods}

Effluent solution samples and extracts from the sand samples were analyzed for DNT with the highperformance liquid chromatography based EPA Method 8330. All DNT analyses were performed by Accutest, in Orlando, FL, in accordance with EPA guidelines (USEPA 2009b). In this method, aqueous samples are diluted with acetonitrile, filtered, and then separated on a C-18 reverse column. Analyte concentrations are determined at $254 \mathrm{~nm}$ wavelength with an ultraviolet detector and confirmed on a secondary $\mathrm{CN}$ reverse phase column (USEPA 2009b). Soil samples are extracted with acetonitrile in an ultrasonic bath and then processed in the same manner. For quality control purposes, analyses of each sample batch included a method blank, a blank spike, and matrix spike.

Bromide analyses were performed by the Water Quality Laboratory at the University of Tennessee using ion-exchange chromatography (DIONEX100) based method EPA 300.1 (USEPA 2000). All samples 
were brought to $5-\mathrm{mL}$ volume with deionized water and passed through a $0.45-\mu \mathrm{m}$ particulate filter. Samples were then injected into a stream of carbonate eluent and passed through an ion exchange column (IonPac AS9-HC Analytical, $4 \mathrm{~mm}$ id) and into a conductivity detector. Equipment calibration was performed after every ten samples using five concentrations prepared from the stock standard solution (Aldridge).

\section{Results}

\subsection{DNT Recovery in the Effluent}

The primary objective of this research was to determine whether DNT, a surrogate ER material, could be transported through simple granular media in the particulate form. We assume that DNT particles of diameter less than the filter pore size $(0.2 \mu \mathrm{m})$ are dissolved. The difference between concentrations measured in samples that were filtered (dissolved DNT) and unfiltered (total DNT, consisting of dissolved DNT and DNT particles $>0.2 \mu \mathrm{m}$ ) concentrations is used to infer the presence of particulate DNT in the effluent samples. Conversely, overlapping curves for total and dissolved DNT would imply that all the DNT is dissolved and that no particle transport occurred. Results for total and dissolved DNT in effluent samples from the experiments in fine sand (FS), medium sand (MS), and glass beads (GB) are presented in Fig. 2a-c, respectively. Values are plotted as DNT concentration (milligrams per liter) versus pore volume of effluent, with error bars to represent analytical error based on the quality control standard calibrations. Considering the analytical error, a difference between total and dissolved DNT concentrations was detected in two of the experiments (MS and GB), suggesting that both particles and dissolved DNT were transported through the columns. The error bars for total and dissolved DNT in FS, however, are relatively large, indicating that particle transport was within the analytical error (Fig. 2a). DNT concentrations reached a plateau by the second pore volume of effluent and then remain relatively constant for the duration of the experiments in the fine and medium sand columns. Effluent samples from the glass bead experiment exhibit a spike in DNT concentration before stabilizing at slightly lower levels. Overall,
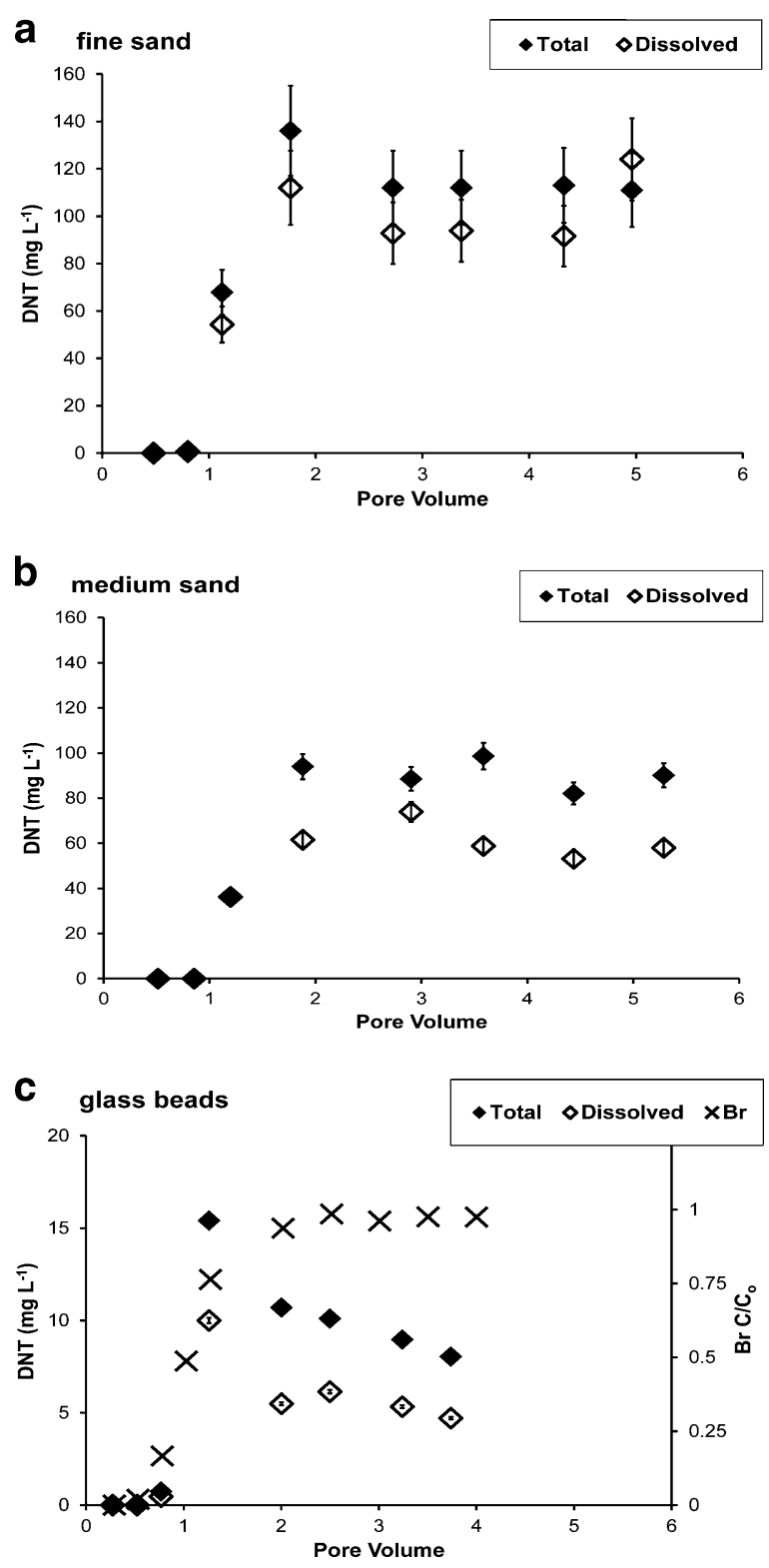

Fig. 2 DNT effluent results. DNT concentrations for unfiltered and filtered effluent samples presented as unfiltered and filtered sample DNT concentration versus pore volume of effluent (a fine sand, b medium sand, and $\mathbf{c}$ glass beads). $\mathbf{c}$ also includes bromide breakthrough data presented as sample concentration normalized to the influent concentration $\left(C / C_{\mathrm{o}}\right)$ versus pore volume of effluent. Note scale difference for c DNT concentrations

mass balance calculations indicate the DNT fraction recovered in the effluent was less than $3 \%$ of the total mass applied to the columns (Table 2).

The breakthrough of a non-reactive $\mathrm{Br}$ tracer in the glass bead experiment is included in Fig. 2c as sample 
Table 2 Mass balance results for DNT tracer experiments

\begin{tabular}{lccc}
\hline & FS & MS & GB \\
\hline Total mass applied to column ${ }^{\mathrm{a}}(\mathrm{mg})$ & 468 & 431 & \\
Mass recovered in effluent $(\mathrm{mg})$ & & & \\
Total & $12.9(2.8 \%)$ & $10.0(2.31 \%)$ & $1.1(0.3 \%)$ \\
Dissolved & $11.9(2.55 \%)$ & $6.77(1.57 \%)$ & $0.65(0.15 \%)$ \\
Particulate & $0.99(0.21 \%)$ & $3.19(0.74 \%)$ & $0.44(0.10 \%)$ \\
Mass recovered in sand $(\mathrm{mg})$ & $366.2(78.2 \%)$ & $286.4(66.4 \%)$ & $224.8(51.5 \%)$ \\
Total mass recovered in effluent and sand (mg) & $379.1(80.9 \%)$ & $296.4(68.7 \%)$ & $225.9(51.7 \%)$ \\
\hline
\end{tabular}

Presented are the mass balance results for the DNT tracer experiments. Total effluent values were determined using the unfiltered effluent sample concentration data. Likewise, the dissolved values are from the filtered effluent sample concentration data, and the particulate values are inferred from the difference between the total and dissolved values

${ }^{a}$ For each experiment, the total mass is the amount of DNT applied to the top of the columns

concentration normalized to the influent concentration $\left(C / C_{\mathrm{o}}\right)$ versus pore volume of effluent. A qualitative comparison of the effluent breakthrough curves suggests that the initial $\mathrm{Br}$ breakthrough roughly coincides with the arrival of DNT in the effluent. The coincident $\mathrm{Br}$ and DNT breakthrough suggest DNT behaves in a non-reactive fashion under these experimental conditions.

We also examined the ratio of dissolved to total DNT concentrations in effluent samples versus pore volume for all three experiments (Fig. 3). Higher ratio values indicate a greater proportion of dissolved DNT in the effluent. Overall, the dissolved to total DNT concentration ratio for each pack type is fairly constant throughout the experiment, indicating a consistent amount of particulate DNT is detaching over time.

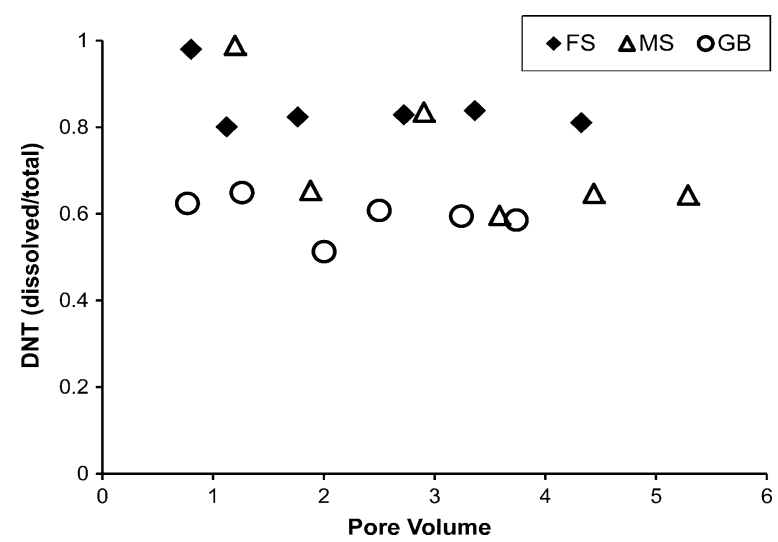

Fig. 3 Comparison of dissolved DNT proportions in effluent. Ratio of dissolved to total DNT concentrations, in effluent samples experiments in fine sand (FS), medium sand (MS), and glass beads (GB), versus pore volume of effluent
Effluent from the fine sand experiment had the highest proportion of dissolved versus particulate DNT, indicating that smaller grain sizes inhibited the transport of particles. In contrast, effluent from the glass bead experiment had the lowest proportion of dissolved DNT, indicating that larger grain sizes tended to promote the transport of particles. Results for effluent from the medium sand experiment were intermediate. Based on mass balance results, particulate DNT accounts for approximately $41 \%$ of the DNT mass recovered in the effluent from the glass bead column, $32 \%$ for the medium sand column, and less than $8 \%$ for fine sand column (Table 2). Paired $t$ test statistical analysis was used to compare the dissolved and total effluent aliquots from each experiment. A difference in means across the paired observations was considered significant for $p$ values $<0.05$. The results indicate that the concentration difference between the filtered and unfiltered effluent samples is highly significant $(p<0.01)$ for the medium sand and glass bead experiments, but only marginally significant $(p=0.06$ ) for fine sand samples. The $t$ tests were consistent with the quality control analyses (Fig. 2), in which particle transport was conclusive in MS and GB. In FS, the error bars for total and dissolved phases nearly overlap, indicating that the potential for particle transport was within analytical error. The statistical analysis and the mass balance calculations suggest that as grain size increases, particulate transport accounts for a larger portion of the DNT detected in the effluent. Conversely, lower effluent concentrations of total and dissolved DNT were observed in glass beads versus the both sands (Fig. 2), and total DNT mass recovered 
in the effluent decreased with increasing grain size, from $2.8 \%$ in fine sand to $0.3 \%$ in glass beads with medium sand being intermediate (Table 2).

\subsection{DNT Distribution in Column Materials}

Distribution of DNT in the column materials are presented as DNT concentration (milligrams per kilogram) versus depth (centimeters) (Fig. 4). The solid phase from each column exhibits a non-linear decrease in DNT concentration with depth. In all cases, the bulk of the DNT mass is retained in the top $2 \mathrm{~cm}$ of the column material, near where it was emplaced. Below the first few centimeters, DNT concentrations in each column are more uniform. In the fine sand column, DNT concentrations below $6 \mathrm{~cm}$ are approximately the same $\left(\sim 2 \mathrm{mg} \mathrm{kg}^{-1}\right)$. In the medium sand column, DNT concentrations below $8 \mathrm{~cm}$ are approximately the same $\left(\sim 0.5 \mathrm{mg} \mathrm{kg}^{-1}\right)$, but less than observed in FS. In the glass bead column, concentrations below $4 \mathrm{~cm}$ are less than the minimum detection limit (MDL) of $0.04 \mathrm{mg} \mathrm{kg}^{-1}$.

It is impossible to determine via the analytical methods used in this study whether the DNT in the slices of column material occurs as dissolved/adsorbed or particulate DNT. The occurrence of dissolved and particulate DNT transport, as evidenced from our effluent results, suggests the column in solid phase should contain a combination of both. Most of the solid-phase samples in the upper portions of the columns $(\sim 2-8 \mathrm{~cm})$ exceed the solubility of DNT, suggesting that particulate DNT is present. Therefore, the observed spatial distribution of DNT may be largely attributed to the transport and subsequent retention of DNT particles at depth in the column material.

Overall, mass recovery of the DNT decreased with increasing grain size, from approximately $81 \%$ for the fine sand to $52 \%$ for the glass beads with the medium sand intermediate. The $<100 \%$ mass recovery is likely due to DNT loss during sample processing prior to analysis. One possible path for DNT loss occurs during the sectioning of frozen column into subsamples for analysis. The porous media becomes less coherent as the column begins to thaw during the process; this is especially true of the coarser media. Due to this, it is possible small amounts of sample were lost. Another potential pathway for DNT loss is in the standard operating procedures of EPA method 8330 which require the decanting of any free liquid from soil samples prior to analysis. The "soil" samples from our experiments consisted of loose sand/glass beads, material unlikely to retain a great deal of water against gravity; again, this is especially true of the coarser media. Therefore, the decanting process could easily result in the loss of both dissolved and particulate DNT from the sand samples.

\section{Discussion}

There are very few transport experiments using particulate explosives materials present in the literature for
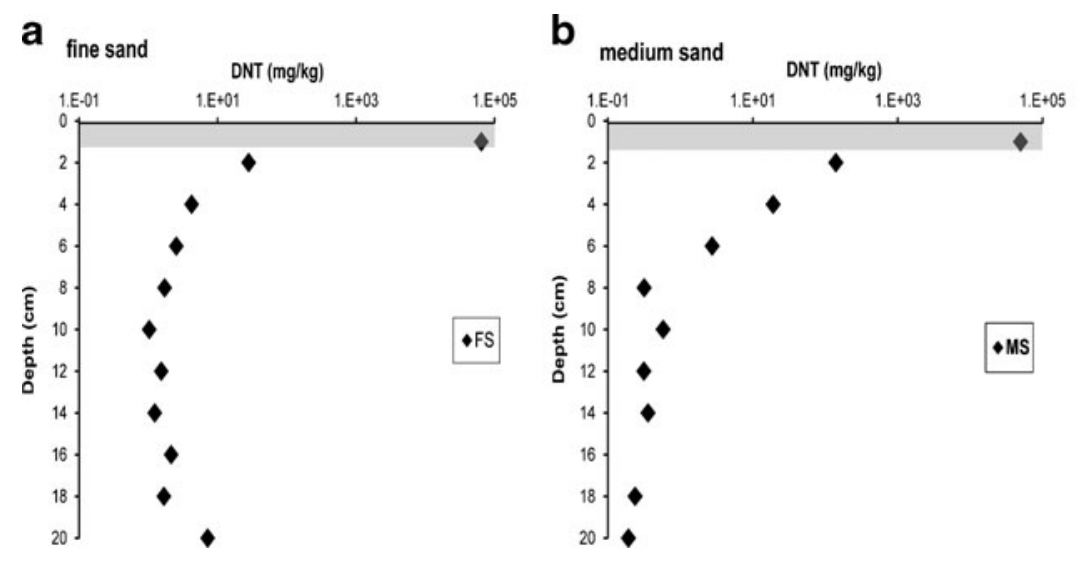

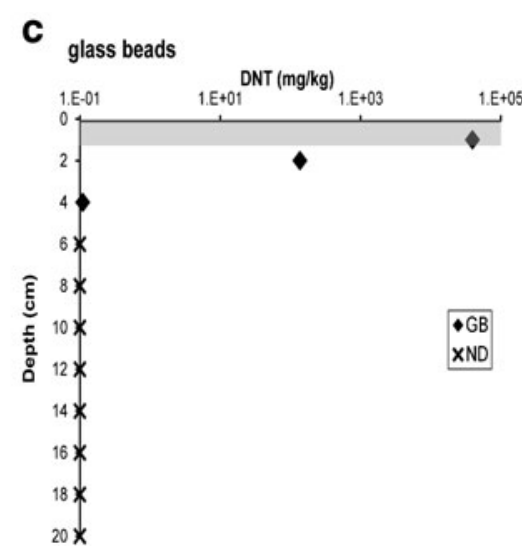

Fig. 4 DNT retention profiles. DNT distribution in sand samples from experiments in fine sand (FS), medium sand (MS), and glass beads (GB), presented as DNT concentration in each $1-\mathrm{cm}$ segment of sand (milligrams per kilogram) versus depth, in a, b, and c, respectively. Shaded area indicates approximate depth of DNT surface application. Analytical results indicate that GB samples below $4 \mathrm{~cm}$ were non-detect $\mathrm{ND}(\mathrm{MDL}=0.04 \mathrm{mg} / \mathrm{kg})$ 
comparison. Dontsova et al. (2006) performed transport experiments using $\mathrm{CB}$ residues from low order detonations which were applied to column materials in both the dissolved and solid phase. However, the size of the CB particles was relatively large $(0.25$ to $2 \mathrm{~mm})$, which is expected to lead to high retention in soil pores. The effluent samples were not analyzed for the presence of particulate material (e.g., using filtered aliquots), so it is unknown whether particle phase transport of $\mathrm{CB}$ occurred in these experiments.

Previous research indicates that particle transport is controlled by a number of factors including: size of colloids, size of grains or pores, surface characteristics of colloids/media, solution chemistry, and flow rate (Tufenkji and Elimelech 2005; McCarthy and McKay 2004; McCarthy and Zachara 1989; McDowell-Boyer et al. 1986). Generally, there tends to be an optimum particle size for transport, with larger particles lost to gravitational settling and physical straining, while particles smaller than the optimum size are preferentially lost due to electrostatic/hydrophobic attachment to soil surfaces. Due to the large number of parameters influencing particle transport, the accuracy of predictive models is limited. However, typically, as the grain size of the media increases, retention due to all mechanisms tends to decrease because the pores are larger and there is a lower likelihood of suspended particles coming in contact with the media. In Dontsova et al. (2006), it is likely experimental conditions were not ideal for particle transport due the size of the residues and the fine-grained media (loamy sand and silt) used in the columns, therefore particulate transport would not be expected to occur.

In experiments investigating the effect of differentsized granular media on the transport of microspheres, both Bradford et al. (2002) and Knappett et al. (2009) found a positive relationship between increased grain size and peak effluent concentrations for column experiments conducted with microspheres in granular porous media. Likewise, studies investigating the transport of microorganisms, such as Cryptosporidium parvum in sandy aquifers, showed decreased retention with increased median grain size (Kim et al. 2010). The effluent results for this study using DNT particles are in general agreement with these previous works. As expected, the DNT particulate fraction in effluent samples increased with increased size of granular media (Fig. 3). Moreover, the proportion of particulate material in the effluent remains consistent for the duration of the experiment, indicating a relatively constant rate of mobilization and transport from the top centimeter of the column.

Based on previous colloid studies, we would also expect to see decreasing retention of particulate ER with increasing grain size of column material. In this investigation, the decrease in retention is most evident in the lower portions of the columns ( $\geq 8 \mathrm{~cm}$ depth), with DNT concentrations highest for the fine sand and below analytical detection limits for the glass beads (Fig. 4). Results for our sand samples are consistent with the findings of Bradford et al. (2002) and Johnson et al. (2007) in which microsphere retention profiles in porous media exhibited a non-linear decrease in colloid concentration with mass retention strongest near the point of input. Bradford et al. (2002) attributed this initial removal to physical straining of larger particles in blocked or dead end pores. They proposed a threshold straining value, consisting of the ratio of the particle size to the median grain size $\left(d_{\mathrm{p}} / d_{50}\right)$, where colloid retention increases exponentially as $d_{\mathrm{p}} / d_{50}$ values exceed 0.005 . The DNT powder applied to our columns was comprised of a relatively wide range of particle sizes (approximately 2 to $50 \mu \mathrm{m}$ ) (Fig. 1). Nearly all $d_{\mathrm{c}} / d_{50}$ values for the fine sand exceeded the 0.005 threshold value, while only the upper limit exceeded 0.005 for the glass beads, suggesting straining should be very significant for the fine and medium sand, but much less so for the glass beads. This is consistent with our observations for the fine and medium sand, with $>66 \%$ DNT mass retained in the top quarter of column material. However, straining was also significant for the glass beads (Fig. 4). One possible explanation for this greater than expected straining is that the larger pore structures of the glass beads allowed the DNT particles to form aggregates. Microscopic imagery from particle size distribution analyses reveals that DNT particles have a tendency to flocculate when immersed in water. Even with the addition of $1 \%$ BSA as a surfactant, the combination of high DNT concentrations in the top layer of column material plus the larger pore structure of the glass beads may have enabled the formation of DNT particle aggregates, thus increasing the $d_{\mathrm{p}} / d_{50}$ value. Aside from this difference in spatial distribution, overall, our findings are congruent with those of published colloid 
research and indicate potential for the transport of ER particulate material.

Unlike previous colloid research, which has focused on the transport of non-dissolving solids (e.g., microspheres, pathogens) or dissolved contaminants sorbed to soil materials (e.g., clay particles, organic matter), the particles investigated here are soluble, with transport occurring in both the dissolved and particulate phases. An unanticipated observation of this study was that, while the proportions of particulate versus dissolved concentrations increased with increasing grain size, the total concentration of DNT in the effluent solutions was found to be inversely related to grain size. This was surprising as the results reported for above mentioned studies suggest that larger pore sizes should enhance the migration of DNT particles, and as particles are transported, concurrent dissolution of DNT would also be expected. Because influent flow rates were identical for each experiment, we expected a similar rate of DNT dissolution and hence similar concentrations of dissolved phase DNT in effluent solutions. Since breakthrough of the DNT and $\mathrm{Br}$ were coincident (Fig. 2c), attenuation due to chemical adsorption is not likely. On the other hand, if DNT particles do form aggregates in the larger pore structures of the coarser media, this might slow dissolution by decreasing the effective surface area.

Numerous studies have investigated the dissolution kinetics of ER chemicals (Lynch et al. 2002; Lever et al. 2005; Furey et al. 2008; Taylor et al. 2009a, b; Dontsova et al. 2009). These studies have yielded dissolution rates that appear to range over several orders of magnitude (we calculated approximate dissolution rates ranging from $1 \mathrm{E}-4$ to $1 \mathrm{E}-$ $9 \mathrm{mg} \mathrm{cm} \mathrm{s} \mathrm{s}^{-1}$ ) depending on the experimental conditions. The fastest rates of dissolution are typically produced by studies where ER chemicals are dissolved in stirred water baths, while the slowest rates come from experiments involving transport through porous media or those designed to simulate the effects of rainfall. For the most part, these studies have determined dissolution rates using individual ER fragments from detonations or pure crystals of ER chemicals in the centimeter to millimeter size range. In theory, the smaller particles used in the work presented here should have allowed for accelerated dissolution of the total DNT mass applied to the columns due to increased surface area. Nonetheless, the results of our experiment show that even micronscale particles can persist in saturated, steady flow conditions for a limited time. In addition, the majority of the DNT mass applied to the columns remained undissolved over the timescale of the experiment. If occurring, the formation of DNT aggregates could influence both particulate mobility and dissolution.

\section{Conclusions}

The conceptual model presented by previous studies investigating the mass transfer of ER from surface soils to underlying aquifers is based on the premise that transport occurs solely in the dissolved phase. Our results show that transport of DNT, a surrogate for ER, can occur as both dissolved and particulate phases. This suggests that it may be possible for fine explosives residues, produced directly by detonation or though the weathering of larger ER fragments, to migrate as particulate material.

The findings of this study are preliminary because many uncertainties remain regarding the mechanisms governing the dissolution and mobility of particulate ER material. In this research, a single component surrogate, DNT, was used in the place of actual ER. More study is needed to determine if residues of $\mathrm{CB}$ or other explosives residues exhibit the same potential for transport. In addition, the experiments presented herein were designed to create optimal conditions for colloid transport. Future experiments, conducted under more realistic conditions (i.e., at lower flow rates and solution chemistry typical of soil pore water - without the use of artificial surfactants), are required to determine whether the conventional conceptual model for ER should be expanded to include particulate transport.

Acknowledgments The authors would like to express their appreciation to Drs. Steven Minkin and John Biggerstaff, with the University of Tennessee, Center for Environmental Biotechnology, for their assistance with this project. We are also thankful to Drs. Guoping Tang and Prasesh Sharma, with Oak Ridge National Laboratory, and Dr. Ed Perfect, with the University of Tennessee, Department of Earth and Planetary Sciences, for their help with the manuscript. The work is funded through Strategic Environmental Research and Development Program (SERDP) Project Number ER-1690. The work was completed at the University of Tennessee in association with Oak Ridge National Laboratory (ORNL). ORNL is managed by the University of Tennessee-Battelle, LLC, under contract DE-AC05-00OR22725 with the US DOE. 
Open Access This article is distributed under the terms of the Creative Commons Attribution Noncommercial License which permits any noncommercial use, distribution, and reproduction in any medium, provided the original author(s) and source are credited.

\section{References}

Bradford, S. A., Yates, S. R., Bettahar, M., \& Simunek, J. (2002). Physical factors affecting the transport and fate of colloids in saturated porous media. Water Resources Research, 38, 1-12.

Clausen, J.L., Korte, N., Dodson, M., Robb, J. \& Rieven, S. (2006). Conceptual model for the transport of energetic residues from surface soil to groundwater by range activities. ERDC/CRREL TR-06-18, US Army Engineer Research \& Development Center, Hanover, NH.

Dontsova, K. M., Pennington, J. C., Hayes, C., Simunek, J., \& Williford, C. W. (2009). Dissolution and transport of 2,4DNT and 2,6-DNT from M1 propellant in soil. Chemosphere, 77, 597-603.

Dontsova, K. M., Yost, S. L., Simunek, J., Pennington, J. C., \& Williford, C. W. (2006). Dissolution and transport of TNT, RDX, and composition B in saturated soil columns. Journal of Environmental Quality, 35, 2043-2054.

Elgrabli, D., Abella-Gallart, S., Aguerre-Chariol, O., Robidel, F., Rogeriuex, F., Boczkowski, J., et al. (2007). The effect of BSA on carbon nanotube dispersion for en vivo and in vitro studies. Nanotoxicology, 1(4), 266-278.

Fetter, C. W. (1994). Applied hydrogeology (3rd ed.). Upper Saddle River, NJ: Prentice Hall.

Furey, J. S., Fredrickson, H. L., Richmond, M. J., \& Michel, M. (2008). Effective elution of RDX and TNT from particles of Comp B in surface soil. Chemosphere, 70, 1175-1181.

Hewitt, A. D., Jenkins, T. F., Ramsey, C. A., Bjella, K. L., Ranney, T. A., \& Perron, N. M. (2005). Estimating energetic residue loading on military artillery ranges, ERDC/CRREL report TR-05-7. Hanover, NH: US Army Engineer Research \& Development Center.

Jenkins, T. F., Hewitt, A. D., Grant, C. L., Thiboutot, S., Ampleman, G., Walsh, M. E., et al. (2006). Identity and distribution of residues of energetic compounds at army live-fire training ranges. Chemosphere, 63, 1280-1290.

Jenkins, T.F., Pennington, J.C., Ranney, T.A., Berry, T.E., Miyares, P.H., Walsh, M.E., Hewitt, A.D., Perron, N.M., Parker, L.V., Hayes, C.A., \& Wahlgren, E.G. (2001). Characterization of explosives contamination at military firing ranges. ERDC/CRREL report TR-01-5, US Army Engineer Research \& Development Center, Hanover, NH.

Johnson, W. P., Li, X., \& Assemi, S. (2007). Deposition and reentrainment dynamics of microbes and non-biological colloids during non-perturbed transport in porous media in the presence of an energy barrier to deposition. Advances in Water Resources, 30, 1432-1454.

Kim, H. N., Walker, S. L., \& Bradford, S. A. (2010). Coupled factors influencing the transport and retention of Cryptosporidium parvum oocysts in saturated porous media. Water Research, 44, 1213-1223.
Knappett, P. S. K., Emelko, M. B., Zhuang, J., \& McKay, L. D. (2009). Transport and retention of a bacteriophage and microspheres in saturated, angular porous media: Effects of ionic strength and grain size. Water Research, 42, 4368-4378.

Lever, J. H., Taylor, S., Perovich, L., Bjella, K., \& Packer, B. (2005). Dissolution of composition B detonation residuals. Journal of Environmental Science and Technology, 39, 8803-8811.

Luning Prak, D. J., \& O’Sullivan, D. W. (2007). Solubility of 4nitrotoluene, 2,6-dinitrotoluene, 2,3-dinitrotoluene, and 1,3,5-trinitrobenzene in pure water and seawater. Journal of Chemical and Engineering Data, 52, 2446-2450.

Lynch, J. C., Brannon, J. M., \& Delfino, J. J. (2002). Dissolution rates of three high explosive compounds: TNT, RDX, and HMX. Chemosphere, 47, 725-734.

McCarthy, J. F., \& McKay, L. D. (2004). Colloid transport in the subsurface: Past, present, and future challenges. Vadose Zone Journal, 3, 326-337.

McCarthy, J. F., \& Zachara, J. M. (1989). Subsurface transport of contaminants: Mobile colloids in the subsurface environment may alter the transport of contaminants. Journal of Environmental Science and Technology, 23(5), 496-502.

McDowell-Boyer, L. M., Hunt, J. R., \& Sitar, N. (1986). Particle transport through porous media. Water Resources Research, 22(13), 1901-1921.

Morley, M. C., Yamamoto, H., Speitel, G. E., \& Clausen, J. (2006). Dissolution kinetics of high explosives particles in a saturated sandy soil. Journal of Contaminant Hydrology, $85,141-158$.

Pennington, J.C., Thorn, K.A., Hayes, C.A., Porter, B.E., \& Kennedy, K.R. (2003). Immobilization of 2,4- and 2,6dinitrotoulene in soils and compost. ERDC/CRREL report TR-03-2, US Army Engineer Research \& Development Center, Hanover, NH.

Snyder, L. R., \& Kirkland, J. J. (1979). Introduction to modern liquid chromotography. New York, NY: Wiley.

Suttiprasit, P., Krishdhasima, V., \& McGuire, J. (1992). The surface activity of $\alpha$-lactalbumin, $\beta$-lactoglobulin, and bovine serum albumin: Surface tension measurements with single-component and mixed solutions. Journal of Colloid and Interface Science, 154, 316-326.

Taylor, S., Lever, J. H., Fadden, J., Perron, N., \& Packer, B. (2009a). Simulated rainfall-driven dissolution of TNT, Tritonal, Comp B and Octol particles. Chemosphere, 75, 1074-1081.

Taylor, S., Lever, J. H., Fadden, J., Perron, N., \& Packer, B. (2009b). Outdoor weathering and dissolution of TNT and Tritonal. Chemosphere, 77, 1338-1345.

Taylor, S., Campbell, E., Perovich, L., Lever, J., \& Pennington, J. (2006). Characteristics of composition B particles from blow-in-place detonations. Chemosphere, 65, 1405-1413.

Taylor, S., Hewitt, A., Lever, J., Hayes, C., Perovich, L., Thorne, P., et al. (2004). Particle size distribution from detonated 155mm Howitzer rounds. Chemosphere, 55, 357-367.

Thiboutot, S., Ampleman, G., Gagnon, A., Marois, A., Jenkins, T.F., Walsh, M.E., Thorne, P.G. \& Ranney T.A. (1998). Characterization of anti-tank firing ranges at CFB Valcartier, WATC Wainwright and CFAD Dundurn, Report \# DREV-R-9809, Defense Research Establishment, Val-Belair, Quebec. 
Tufenkji, N., \& Elimelech, M. (2005). Breakdown of colloid filtration rheory: Role of the secondary energy minimum and surface charge heterogeneities. Langmuir, 21, 841852.

U.S. Environmental Protection Agency (2000). Methods for determination of inorganic anions in drinking water by ion chromatography (300.1, revision 1.0). EPA 815-R-00-014. U.S. Environmental Protection Agency. <http://water.epa. gov/scitech/drinkingwater/labcert/upload/met300.pdf $>$. Accessed on: 25 January, 2011.
U.S. Environmental Protection Agency (2009a) Drinking water standards and health advisories. EPA 822-R-09-011. U.S. Environmental Protection Agency. <http://water.epa.gov/ action/advisories/drinking/upload/dwstandards2009.pdf>. Accessed on: 1 April, 2010.

U.S. Environmental Protection Agency (2009b) Test methods for evaluating solid waste, physical/chemical methods (SW846). U.S. Environmental Protection Agency. $<$ http://www. epa.gov/osw/hazard/testmethods/sw846/online/index. htm>. Accessed on: 12 July, 2010. 